\title{
La posición estratégica de los trabajadores del carbón en Chile. De su fortaleza a la crisis, 1920-1960 ${ }^{1}$
}

Hernán Venegas Valdebenito*

Resumen: Este artículo aborda el comportamiento de los empresarios y trabajadores de la minería carbonífera en Chile, específicamente aquellos que se desempeñaron en la región de Arauco, la principal zona productora de carbón en el país. Muestra como el desempeño de las empresas y los intentos de modernización nacional por la vía de la industrialización, fuertemente dependiente de la producción de combustible, fueron puestos a prueba por las demandas de los trabajadores que se habían politizado y hecho conscientes de la posición estratégica que ocupaban en la economía chilena. Ello fue posible hasta que el carbón fue reemplazado por otras fuentes energéticas.

Palabras clave: Minería. Carbón. Movilización social. Posición estratégica.

\section{Introducción}

La minería del carbón en Chile, en la región de Arauco, inició su larga trayectoria a mediados del siglo XIX. En las primeras décadas del siglo siguiente se había consolidado como actividad económica importante, clave en el funcionamiento de la economía chilena en su conjunto. Sin embargo, tuvo que hacer frente a una serie de inconvenientes de difícil solución, por una parte, aquellos derivados de problemas técnicos relacionados con las características geológicas de los mantos de carbón que en esa zona se internan

\footnotetext{
* Professor do Departamento de Historia, Universidad de Santiago de Chile, Usach. E-mail: hernan.venegas@usach.cl
} 
bajo el mar y hacen difícil y cada vez más onerosa la explotación del combustible (DUPLAQUET, 1907; COMISIÓN DEL CARBÓN, 1926). Por otra, debió enfrentar las restricciones impuestas por el comportamiento de los trabajadores, movilizados, por esa época, en función de sus demandas económicas. Finalmente, los empresarios carboníferos debieron considerar una mayor intervención estatal en el plano de la legislación social y seguridad laboral que, aunque tardía, lentamente fue generando un nuevo marco al que debieron suscribirse las relaciones sociolaborales (YÁÑEZ, 2008).

Como ya se dijo, las Compañías debieron lidiar con el comportamiento cada vez más político de sus trabajadores, frecuentemente asociados al ideario de izquierda, lo que en la década de 1920 fue sistemáticamente relacionado con la "prédica" comunista (FIGUEROA; SANDOVAL, 1987; VENEGAS, 1998).

Las empresas y sus encargados debieron valerse, para el control de los trabajadores, de las alternativas institucionales ofrecidas por un sistema político que, a pesar de sus avances en el plano de la democratización, seguía mostrando debilidades, cuando no regresiones, en el fortalecimiento de los derechos de la población para manifestar sus disconformidades y demandas. Fue precisamente en esas etapas regresivas de la democracia chilena, que las empresas, amparadas por agentes del Estado, frenaron la capacidad organizativa y contestataria de los trabajadores ya sea colocándose al límite de los mecanismos legales, cuando no violándolos directamente. Tal como ocurrió durante la Dictadura de Carlos Ibáñez del Campo, a fines de la década de 1920, y las manifestaciones autoritarias, ejercidas, en los años siguientes, a través de la aplicación de leyes que concedían facultades extraordinarias al Presidente de la República y, finalmente, con la dictación de la Ley de Defensa de la Democracia, en septiembre de 1948 (HUNEEUS, 2009; PAVILACK, 2003).

Después de 1950, la propia modernización industrial a la que esos trabajadores habían ayudado poderosamente a construir, así como las dificultades técnicas de la producción en las minas chilenas y el correspondiente encarecimiento de la extracción del carbón en los distritos mineros de Lota y Coronel, determinó el inicio de su extinción, no solamente como parte de la vanguardia obrera, sino también como componente sociocultural específico del sur de Chile. 
El propósito de este trabajo es reconocer por una parte la importancia estratégica alcanzada por la industria carbonífera y sus trabajadores. Una actividad que llegó su apogeo a partir de los años veinte, pero que debió enfrentar el inicio de su decadencia en las décadas siguientes. El trabajo caracteriza dos de los ciclos de movilización social desarrollados en la zona y que afectaron al desempeño de las Compañías, primero en la década de 1920 y luego en la de los años cuarenta y examina cómo aquellas combinaron, en su afán de control, prácticas integradoras a través de sus Departamentos de Bienestar social con la aplicación de una legislación autoritaria, aunque también con violencia física. En ambas ocasiones lo que se puso en tensión fue la capacidad negociadora de los obreros sostenida en el fortalecimiento de su posición estratégica y la intención de los empresarios y autoridades estatales de subordinar a esos trabajadores e imponer sus reglas.

El concepto de posición estratégica fue desarrollado por John Dunlop en el sentido de que existen trabajadores y actividades económicas que se constituyen en claves dentro de las relaciones industriales establecidas entre obreros y capitalistas y, por extrapolación, en el desenvolvimiento de las actividades económicas.

Referido al ámbito del proceso productivo, la posición estratégica determina la capacidad de algunos operarios, en momentos de conflictos con los patrones, para usar como herramienta de presión la paralización de su propia labor, pero además la de interrumpir las tareas de muchos otros trabajadores y demás actividades productivas en un proceso de encadenamiento paralizador ${ }^{2}$.

El concepto también puede ser utilizado para explicar la capacidad que tienen algunos trabajadores ubicados en centros productores de los cuales dependen una serie de otras actividades, de ahí su capacidad disruptiva de las tareas productivas y, al mismo tiempo, el fortalecimiento de su estrategia negociadora. Por ejemplo, una paralización larga en la minería del carbón podía acarrear - tal como ocurrió - trastornos en el transporte ferrocarrilero y naviero, en la industria fabril, en otros sectores de la minería y la industria de fundición, e incluso en la generación de energía eléctrica, dependiente del suministro de carbón. 
En muchos de estos casos, la paralización del trabajo como herramienta de presión estuvo en abierta relación con las competencias técnicas de los trabajadores o de su ubicación en el proceso productivo, tal como puede ser el caso de la categoría de "barreteros", - encargados de arrancar el carbón en los frentes de explotación- en el interior de las minas. Este tipo de trabajadores, de acuerdo a las estadísticas, siempre fueron mejor remunerados que el resto de los operarios de minas, pero al mismo tiempo, antes de consolidarse el trabajo en serie, o durante su evolución, estuvieron enfrentados al sistema de destajo, operado por contratistas en que las empresas habían delegado las tareas de control social dentro de las minas, de manera que el trabajo, en lo posible no se detuviera jamás (CORIAT, 2001). Con todo, durante el desarrollo de los movimientos huelguísticos, la participación de esa categoría de trabajadores fue clave para el éxito de las paralizaciones.

John Womack (2007, p. 51), en un texto más reciente, profundizó el estudio acerca de las posiciones estratégicas en el sentido de reforzar la idea de que el tema se volvía fundamental cuando los propios trabajadores se hacían conscientes de esa posición y de las oportunidades que se derivaban de ellas. Así, en las relaciones industriales modernas, lo que es propiamente de los trabajadores es su capacidad de acción colectiva, que en términos positivos se traduce en producción, pero en términos negativos en "lo que quita o resta a la producción cuando deja de operar".

El carácter estratégico de la industria carbonífera en un país, como Chile, que buscaba industrializarse se mantuvo al menos hasta que se superó la debilidad para importar de la economía nacional y mientras la todavía incipiente industria petrolera y la producción de energía hidroeléctrica, no fueron capaces de introducir cambios importantes en la oferta energética interna. Ambos fenómenos sólo fueron significativos a fines de la década de 1950.

El escrito esta organizado en cuatro apartados, en el primero de los cuales se entregan antecedentes de la minería del carbón, su localización y su importancia dentro de la economía chilena; en el segundo y tercero se examina el primer ciclo de movilizaciones y la influencia comunista. En el cuarto se entregan antecedentes de un segundo ciclo de movilización y los esfuerzos estatales por 
detenerlo. Finalmente algunas conclusiones que hemos considerado importantes.

\section{Estructura empresarial, mercados e importancia estratégica de la minería del carbón}

La región minera es una vasta zona geográfica ubicada unos cincuenta kilómetros al sur de la ciudad de Concepción y que se abre en los centros mineros de Lirquén, Cosmito y El Rosal y se extiende hasta Lebu, un poco más al sur de lo que ha sido reconocido como el Golfo de Arauco.

Se trata de una minería que tuvo sus inicios durante la primera mitad del siglo XIX, constituida principalmente por los distritos y ciudades mineros de Lota y Coronel, y algunos centros menores ubicados al norte del río Bío-Bío, que generaron más del 90\% de la producción nacional de carbón, de allí su incidencia en las actividades económicas y la importancia concedida por las autoridades al comportamiento de sus empresarios y trabajadores (MAZZEI, 1997; 1998; 1999).

En sus comienzos el espacio puede ser reconocido como de frontera minera, en que el avance hacia el sur, por parte de actores económicos relacionados con el Estado de Chile, penetró en el borde costero de la región (ORTEGA, 1992). La instalación de las primeras estructuras mineras en Coronel y en Lota, formaron parte de la ocupación del territorio y de la expulsión, a través de distintos mecanismos, de la población originaria mapuche en aquellos espacios o la integración de aquella como mano de obra en los nuevos centros industriales.

En los cuarenta años siguientes, los trabajadores asociados a estas actividades alcanzaron a poco más de 16.000 , aunque para entonces, la población total de los distritos más importantes, Lota y Coronel, ya había superado las cien mil personas (ARANCIBIA, 1921; CENSO DE LA REPÚBLICA DE CHILE, 1920)³.

Con todo, lo que cabe señalar es que la región mostró un notable dinamismo asociado a las actividades extractivas del carbón, a 
las redes de transporte involucradas, - especialmente el ferrocarril de Curanilahue a Concepción ${ }^{4}$, construido por la Compañía Arauco, traspasado a la Compañía Los Ríos de Curanilahue y luego monopolizado por los industriales carboníferos de Lota (VENEGAS, 1998) - y a la intensa actividad portuaria que significaba inicialmente la extracción de un millón de toneladas anuales.

La década de 1920, marcó profundos cambios en la estructura económica del país, lo que quedó expresado en las transformaciones del modelo de acumulación capitalista. La inestabilidad y decaimiento del sector exportador introdujo profundas presiones sobre los sectores de la economía que debían su razón de ser al éxito de aquellas iniciativas. Así entonces, las empresas carboníferas tuvieron de dulce y agraz. Su situación se movió de acuerdo a los impactos provocados por los choques externos y las limitaciones para importar, o al ritmo de las fases de expansión y contracción experimentadas por la economía chilena, tal como ocurrió a principios del período o en los difíciles momentos sufridos entre 1926 y 1927. La situación empeoró finalmente cuando sobrevino la crisis de naturaleza más estructural en 1930 cuya recuperación no se experimentó sino hasta un lustro después. Como haya sido, la industria del carbón se movía con impulsos ajenos, y adecuaba sus expectativas, incluso aquellas de carácter especulativo, a los ciclos externos ${ }^{5}$.

Frente a una crisis que parecía permanente y a las condiciones de un mercado bastante errático, aunque en crecimiento, las grandes empresas mineras iniciaron en este período una agresiva campaña para imponerse en el control de este sector energético. Ello llevó a que, por ejemplo, La Compañia Minera e Industrial de Chile, más adelante Compañia Carbonifera e Industrial de Lota (1933), recompusiera su estructura y aumentara su capital hasta 295.000.000 de pesos, que mantuvo como capital nominal en las décadas siguientes ${ }^{6}$. La Compañia Carbonífera y Fundición de Schwager hizo otro tanto aumentando su capital hasta 120.000 .000 de pesos, reuniendo entre ambas el $80 \%$ de la producción total de carbón en el país. Al mismo tiempo, empresas de menor dimensión fueron absorbidas por estos dos grandes complejos, tal como sucedió con La The Arauco Company Limitada y la Compañia Carbonera Los Ríos de Curanilabue, que manejaba además el ferrocarril de Curanilahue a Concepción un verdadero monopolio 
del transporte local (COMISION DEL CARBON, 1926). Desde el punto de vista de sus resultados conviene señalar, que por lo menos desde 1911 hasta 1921, en que empezaron a ocurrir las adecuaciones ya señaladas, las Compañías, gozaron de un amplio margen de utilidades, claramente rayando en la especulación, especialmente en el transcurso de la Primera Guerra Mundial' ${ }^{7}$. Este desempeño, sin embargo, comenzó a obscurecerse luego de terminada esa primera etapa especulativa, motivado, entre otros aspectos, por la pérdida de uno de los grandes mercados nacionales asociados a la demanda de carbón, como lo era la industria salitrera y, por el aumento de las movilizaciones por mejoras laborales impulsadas por los trabajadores del sector, fenómeno que tuvo su corolario en el fortalecimiento de la actividad sindical y de las movilizaciones sociales desarrolladas por los mineros carboníferos.

Una vez superado los estragos provocados por la Gran Depresión, las actividades económicas nacionales volvieron a retomar el ritmo de crecimiento previo al desastre económico, aunque esta vez su nudo articulador, estuvo en la actividad fabril. Así entonces, a mediados de la década de 1930, cuando ya se había iniciado la etapa de recuperación la economía chilena, se trató de favorecer el tránsito de su estructura desde un modelo de economía exportadora a otro sustitutivo de importaciones, tal como lo sintetiza Gabriel Palma (1982). En ese contexto (1930) los principales rubros consumidores de carbón nacional estaban representados por los ferrocarriles del Estado, las empresas de gas y electricidad, la marina mercante nacional y la industria fabril, con un 24,$5 ; 9,98 ; 15,91$; y 13,72 por ciento, respectivamente, sobre un total de 1.422 .458 de toneladas de carbón ${ }^{8}$. Dieciséis años después, aunque considerando solo la realidad de la Compañía Carbonífera e Industrial de Lota, con una producción de 876.950 toneladas de carbón, los porcentajes de destino solo habían cambiado parcialmente. Los ferrocarriles del Estado representaban el 35\% de sus ventas de combustibles, las compañías de gas y electricidad, el 14,5\%, la Marina Mercante Nacional, el 11,3\%, mientras que la industria fabril ampliaba su representación en el mercado, para esta sola empresa, a poco más de un $24 \%$, es decir la dependencia del carbón nacional para la producción y movilización industrial se había acentuado notoriamente ${ }^{9}$ La 
producción total de carbón, durante el año 1946 fue de 1.965.865 toneladas de las cuales el $92,8 \%$ provenían de los yacimientos de Concepción y Arauco ${ }^{10}$.

Es decir, en el periodo de la modernización de la economía chilena, con un eje articulador sustentado en la industria fabril, la oferta de carbón seguía cumpliendo un rol estratégico, y por lo mismo, la posición de los trabajadores carboníferos dentro del engranaje productivo se había fortalecido.

No obstante lo anterior, a lo largo de todo el periodo, las grandes Compañías mantuvieron el control de la actividad, logrando incrementar la producción, que en su conjunto se acercó a los dos millones de toneladas, abasteciendo una parte importantísima del consumo nacional, aunque a precios que indirectamente promovieron la búsqueda de nuevas alternativas energéticas (VENEGAS, 1998). Así, el funcionamiento sin pausa y la disciplina de sus trabajadores se convirtió en una necesidad esencial, no solo para el resultado económico de las compañías carboníferas, sino también para otras actividades importantes, especialmente el transporte y la producción industrial, por lo menos hasta fines de la década de 1950 en que ambas empresas enfrentaron los problemas más serios de viabilidad productiva. La crisis de la grandes Compañías fue manifiesto hacia fines de esa época, a pesar de que el volumen de su producción no se redujo. Sus problemas fundamentales estaban asociados a los elevados costos de producción y a las dificultades para encontrar compradores. Las soluciones planteadas por las propias Compañías fueron radicales. Por una parte, aceptaron la integración estatal en términos asociativos; declararon abiertamente la posibilidad de cerrar las minas, con el costo social y económico que ello significaba, y por último, desde 1960 levantaron la idea de fusionar las dos Compañías más importantes. Teniendo como propósito abaratar los costos productivos; enfrentar más adecuadamente un mercado en regresión; iniciar nuevos procesos de modernización y conseguir recursos externos avalados por sus mejores resultados de operación. La opción fue esta última, así, en 1964 se formaba la Compañía Carbonífera Lota Schwager, que anunció el comienzo del fin de la industria y de la capacidad de sus trabajadores para mantenerse como una fuerza social estratégicamente poderosa ${ }^{11}$. 


\section{El primer ciclo de movilización social y la fortaleza estratégica de los mineros carboníferos}

La agitación social de los trabajadores carboníferos no fue algo nuevo para el período histórico que nos ocupa. A pocos años de haberse iniciado las tareas extractivas los trabajadores carboníferos dieron muestra de descontento frente a las situaciones que los aquejaban, las que podían ser motivadas desde el incumplimiento de los acuerdos laborales-salariales contraídos con los patrones, hasta los malos tratos recibidos en las faenas o en las calles, durante el ejercicio de su ocio. Si bien en las primeras etapas de conformación de la industria minera estas manifestaciones carecieron de estructura y organización y respondieron más bien a acciones espontáneas, - tal como había ocurrido en otros espacios mineros e industriales de otras experiencias como las del desierto nortino en los ciclos de la plata y del cobre (ILLANES, PINTO) -, ellas fueron adquiriendo una fisonomía distinta desde que aparecieron las primeras formas de organización y acción colectiva (FIGUEROA; SANDOVAL, 1987). Así, un cambio significativo pareció operar a principios del siglo XX. La formación de la Federación Mancomunal de Trabajadores de Lota y Coronel, (una forma de organización sindical), en mayo de 1902 y el desarrollo de la huelga obrera en junio del mismo año, dio a la movilización colectiva de los trabajadores un marcado carácter reivindicativo, aunque con el tiempo fueron derivando hacia la incorporación de expresiones de naturaleza política que demandaban la transformación de las relaciones trabajador-empresa o directamente la transformación de la sociedad en su conjunto ${ }^{12}$. Se exigió el reconocimiento de derechos políticos en un marco democrático y, al mismo tiempo, se asistió al reforzamiento de propuestas que claramente se fueron "contaminando" de un lenguaje que terminó por promover el establecimiento de una sociedad socialista.

El período 1920-1930 fue heredero de estas expresiones, aunque obviamente, respondió a las propias dinámicas de una sociedad que estaba experimentando - con avances y retrocesos -, importantes cambios a nivel nacional.

Como en otras regiones del país, en la zona carbonífera, durante las primeras décadas del siglo, la dirección de los conflictos 
y sus soluciones estuvieron relacionadas con la influencia de los partidos de izquierda como el Partido Demócrata y sus líderes locales. Sin embargo, en la coyuntura de las grandes movilizaciones de 1920, ese liderazgo fue remplazado por el de los dirigentes de la Federación Obrera de Chile (FOCH), claramente asociados, primero, al Partido Obrero Socialista (POS), refundado en 1922 con el nombre de Partido Comunista de Chile (PCCh), aunque la mayoría de ellos, ciertamente mantenían la doble militancia de dirigentes laborales y agitadores políticos (FIGUEROA; SANDOVAL, 1987; VENEGAS, 1999).

Cuando se produjeron los fenómenos huelguísticos de 1920 en la región fue la FOCH, y sus cerca de 30 Consejos Federales, la que asumió la organización y conducción de La huelga, y la articulación de una movilización que incluía toda la zona del carbón, en un conflicto que habían iniciado los trabajadores de la Compañía Los Ríos de Curanilahue, agrupados en el Consejo Federal No1 de la FOCH, pero que se extendió desde Coronel a Lebu, es decir a toda la región minera (FIGUEROA, 2009). Una movilización en que los trabajadores además fueron secundados por un componente social muy diverso incluyendo sus propias familias y aliados en otros campos laborales, familias agrarias, aunque también, pescadores, obreros industriales de la región y de otras partes del país (FIGUEROA, 2009; CARRASCO; FIGUEROA, 1998; VENEGAS, 1999). Así entonces, el ciclo de movilizaciones en la zona carbonífera, se conectó con otros fenómenos de agitación y politización nacional, como las organizadas por la Asamblea Obrera de Alimentación Nacional que operaba desde 1918 y las huelgas regionales organizados por la FOCH. Por ejemplo, a fines del año 20 y, de acuerdo a datos oficiales, una huelga regional movilizó a cerca de 40 mil trabajadores entre los que se contaban los carboníferos de Coronel, Lota, Curanilahue, Lirquén y Cerro Verde, pero además obreros de las fábricas textiles, azúcar, molinos, ferrocarriles, fábricas de cerveza, gremios marítimos y jornaleros de aduana, operarios de los diques en Talcahuano y de varias empresas de menor magnitud ${ }^{13}$. El punto de partida de aquella efervescencia social había sido la paralización que ocho meses antes habían protagonizado los obreros carboníferos en la denominada Huelga Larga de 1920, profundamente enraizada en la memoria social 
del los habitantes de la región y que entonces habían dado una prueba más que suficiente de su capacidad estratégica en sectores tan sensibles como la energía, el transporte y la industria. La huelga larga de inicios del año 20 en la región se extendió 87 días poniendo en jaque a las Compañías carboníferas que resintieron sus ingresos, afectando también el abastecimiento normal de combustible para las distintas actividades productivas nacionales. Un conflicto de igual magnitud se vivió al año siguiente, en que casi la totalidad de los trabajadores carboníferos de la región paralizaron nuevamente por más de dos meses sus actividades productivas, provocando el desconcierto de empresarios y de las autoridades nacionales (FIGUEROA; SANDOVAL, 1987; VENEGAS 1992; 1999)

Las movilizaciones continuaron por lo menos hasta 1927, en que la espiral se detiene, por varias razones: entre otras cosas por su propio decaimiento y por los efectos de la represión impuesta desde la dictadura del General Carlos Ibáñez (1927-1931), aunque también debido a que la crisis económica disminuyó los días del mes trabajados en la minería a 22 o 23, lo que supuso el despido de un enorme número de trabajadores o el cierre de centros mineros de menor magnitud. La causa a más largo plazo, sin embargo, fue la implementación de una nutrida legislación social que brindó algunas mejorías a la situación de los trabajadores y distendió el conflicto social (POBLETE, 1949; YÁÑEZ, 2008).

\section{La expansión de la marea roja. La crisis de 1920 y los primeros llamados de alerta}

Con todo, como ya se señaló, esta época temprana de movilización social, fue permeada por la influencia del POS y luego del Partido Comunista, que no sólo estuvieron presentes en la agitación y organización, de las actividades, sino que también contagiaron con su discurso la actividad sindical minera, mientras que en el corto plazo, cientos de obreros se habían hecho comunistas.

Hacia 1927, cuando ya se había establecido la dictadura de Carlos Ibáñez del Campo, las autoridades de la Dirección del Trabajo, 
seguían refiriendo las desastrosas condiciones de vida en la región carbonífera, y al mismo tiempo alertaban acerca del "desarrollo de las ideas comunistas y subversivas". En Agosto de ese año, el Inspector "Rejional" del Trabajo, Guillermo Cruz A., comunicaba a su superior en la ciudad de Concepción, acerca de una serie de dificultades que entorpecían el normal funcionamiento de la actividad minera y que gravitaban en el deterioro de la calidad de vida de los trabajadores. Cabe hacer notar, que la mayor parte de las condiciones manifestadas en esta verdadera denuncia, es posible encontrarlas reiteradamente en los memoriales de los trabajadores, pero también en las diversas "comisiones" oficiales que inspeccionaron los espacios mineros a lo largo de todo el período que estudiamos. Se encuentran, por ejemplo, en las visitas parlamentarias, los informes técnicos e incluso en los reportes oficiales de personeros enviados a la región como delegados del Gobierno.

Así en este caso, el Inspector Cruz, si bien en una primera parte de su texto manifestaba los avances logrados en el trato de los trabajadores por parte de las empresas (salarios pagados a tiempo; garantías adicionales como la entrega de combustible, agua, asistencia médica; establecimiento de "quincenas" o economatos), al mismo tiempo, dejaba testimonio de las malas condiciones de las viviendas obreras. Para entonces vivían en Lota Alto, es decir el Pueblo controlado por la empresa (Compañía Minera e Industrial de Chile), 11.102 personas, 3.528 obreros dentro de ellas. Otra parte de la población prefería vivir en el pueblo de Lota (Lota Bajo), en que según la autoridad había menos restricciones aunque, de acuerdo a la misma fuente, la calidad de las habitaciones "...en su mayoría no merecen el nombre de viviendas. Son casas construidas con los materiales más heterogéneos, sin luz, sin ventilación i sin desagües i ubicadas en callejones donde rara vez entra el sol"14.

En el distrito minero de Coronel las condiciones no eran mucho mejores de acuerdo a este informante, también existía un espacio controlado por la Compañía Carbonífera y Fundición de Schwager, constituido por las poblaciones de Puchoco, Muelle y Maule, con un total de 7.305 personas. Fuera del "recinto" de Schwager ${ }^{15}$, existía una serie de poblaciones, habitualmente denunciadas por las autoridades y representantes de las empresas como focos de disolución 
social y agitación política. Se trata de espacios como la Colonia, Lo Rojas, Coronel y Villa Alegre, Villa Mora y Buen Retiro, que en conjunto albergaban a una población cercana a los 1.255 habitantes.

A este análisis pesimista, si se quiere, debe agregarse la constatación de las "malas condiciones de trabajo dentro de las minas", de carácter grave en minerales como los de Lebu, pero persistentes en el "resto de la rejión minera": problemas de ventilación, humedad, accidentes de trabajo, enfermedades contagiosas y de naturaleza parasitaria como la anquilostomiasis.

En este marco, el Inspector regional de la Oficina del Trabajo, denunciaba que la agitación política persistía en la zona, a pesar de los cambios institucionales y mecanismos represivos introducidos por la dictadura de Carlos Ibáñez del Campo. De acuerdo al informante,

[...] la Rejión del carbón se presta ampliamente para la propaganda comunista, ya que en un sector relativamente pequeño, como es el comprendido entre Coronel y Curanilahue, trabajan alrededor de 19.000 hombres. ${ }^{16}$

La actividad comunista se había sostenido en el tiempo, no obstante que, a principios de año se había expulsado a numerosos dirigentes de los trabajadores. Los núcleos de propaganda seguían activos, en Coronel, Lota y Curanilahue, tanto es así que el inspector del trabajo sindicaba a estos grupos como organizadores de la huelga de los días 24 y 25 de agosto de 1927, en el mineral de Schwager. "Fue un paro perfectamente organizado en sus menores detalles $i$ en forma tan secreta que solo se tuvo conocimiento de él, el día en que se efectúo", comentó el funcionario público.

No obstante, la autoridad insiste que se trata de obra de agitadores y que el conjunto de la población está relativamente contenta ocupando los canales oficiales de organización y demanda, sin embargo advertía que "las ideas comunistas siguen propagándose. En Coronel, como antaño, se encuentra el centro. Existe ahí el lugarejo denominado La Colonia, que es el refugio de todo el mal elemento que por un motivo u otro es espulsado de algún centro industrial"17. Se debe recordar que para esa fecha muchos de los trabajadores caracterizados por su actividad sindical habían sido separados de 
sus puestos de trabajo tachándoseles como "indeseables" y por lo tanto pesaban sobre ellos serias restricciones para volver a encontrar ocupación. Esta era la otra cara del paternalismo autoritario, los hijos díscolos debían ser separados del resto de la familia.

Otro motivo de alarma del Inspector Regional del Trabajo estuvo relacionado con el rol femenino desempeñado en las tareas de agitación. Según la autoridad eran mujeres las encargadas de difundir la propaganda comunista, camuflando su actuación a través del funcionamiento de cooperativas por medio de las cuales financiaban sus actividades, lo que matiza el rol fundamental desarrollado por las mujeres en torno al género. Aunque no des-miente el constante afán de sometimiento, de la que es objeto la población femenina, a las reglas impuestas por los varones, las empresas y las instituciones, en el sentido planteado por Thomas Klubock para las mujeres de El Teniente, el mayor mineral de cobre en Chile. Allí tanto los reglamentos de las empresas, la actitud de los varones y la connivencia de las autoridades locales y jueces intentaron moldear el comportamiento femenino, especialmente el de la mujer casada ${ }^{18}$.

Esta agitación que era propia de la ciudad de Coronel, tuvo un desarrollo análogo en Lota, aunque con rasgos más limitados. ${ }^{19}$

Las evidencias de estas actividades "disolventes" son múltiples, así por ejemplo, en 1923, una comunicación enviada por el Secretariado "Jeneral" del Consejo Schwager (sindicato), al Ministro del Interior, manifestaba en su lenguaje y contenidos, evidencias de la influencia comunista, en una época en que el partido aún respondía al influjo de Luis Emilio Recabarren (fundador del PCCH) y su opción por la incorporación sistémica. Si se examina el documento es posible aislar varias conclusiones. En primer término, la utilización de un canal oficial para demandar la defensa de los derechos de los trabajadores frente al Estado y contra las Compañías. En segundo término, las demandas tienen una connotación reivindicativa, pero al mismo tiempo están referidas a derechos políticos de los trabajadores, tales como el de organización, reunión, el libre tránsito, así como la difusión de sus ideas a través de la prensa obrera. Por último, frente a los mecanismos restrictivos y controladores de la empresa, la reclamación se organiza en torno a la defensa de lo que hoy se define como estado de derecho. La comunicación de los dirigentes 
de Schwager, como intermediarios de los trabajadores, se expresó de la siguiente manera:

Así que los obreros nos encargaron que preguntáramos a las autoridades administrativas, si existe alguna ley dentro de nuestro país que de lugar a que conviertan en cárceles i en calabozos los establecimientos donde trabajan ciudadanos que han nacido en suelo libre o al menos preguntamos, si acaso habrá alguna lei que pueda remediar estas dificultades que por desgracia acarrean un malestar para todos los trabajadores que quieren disponer de sus libertades i de sus derechos de hombres libres i que no quieren ver lo que ellos llaman su propiedad privada se vaya a convertir en un verdadero presidio para los elementos productores de la industria que son los trabajadores que hoy en día han adquirido más conocimientos de lo que son ellos i de lo que es el patrón ${ }^{20}$.

El documento usa un lenguaje que defiende la democracia representativa, y lo mezcla con otro que claramente se encuentra asociado al reconocimiento de la lucha de clases, propiamente comunista. Sin embargo, la defensa de los derechos de los trabajadores busca insertarse en el marco de un régimen institucional democrático que supuestamente proveía de derechos a los trabajadores, como a cualquier otro ciudadano en virtud de la legislación vigente.

La comunicación denuncia, entre otras cosas, la aplicación de medidas restrictivas implementadas, en este caso por la Compañía Carbonífera y de Fundición de Schwager. Obviamente lo que estaba ocurriendo era que la estrategia empresarial para controlar y dirigir a los trabajadores si bien había desarrollado mecanismos de cooptación e integración como fórmulas de mediano plazo a través del llamado Departamento de Bienestar, en lo inmediato, frente a la amenaza comunista y la movilización de los trabajadores, estaba centrada en la ejecución de estrategias represivas a través de sus propios mecanismos de seguridad o de prácticas radicales como expulsar a los trabajadores de sus puestos de trabajo y desalojar a sus familias de las habitaciones que ocupaban, tal como se estiló en los movimientos huelguísticos de la primera mitad de la década de 1920. 
Con todo, el gran logro de los trabajadores y sus movilizaciones sociales en dicha década, se manifestó en al menos tres planos específicos. Por un lado, en un aumento sustantivo de los niveles de ingresos, por los menos en el plano nominal, aunque claramente, los niveles de inflación y el encarecimiento de los precios, muy rápidamente volvieron los adelantos en esa materia a fojas cero. Un segundo triunfo, aunque burlado por las Compañías con mucha destreza y continuidad, fue el del establecimiento de las ocho horas de trabajo, que obligó a las empresas a establecer tres turnos rotativos, reforzando la idea de que la producción no debía detenerse ${ }^{21}$. No obstante, en los años siguientes y debido a la prolongación de las faenas hasta 500 metros de profundidad y con frentes de extracción ubicados a seis kilómetros de distancia (1947), un trabajador podía prolongar su estadía en el fondo de la mina por 10 u 11 horas continuas, considerando lo que demoraba en descender a su frente de trabajo y luego su recorrido de regreso a la superficie, ese tiempo no era considerado en el pago de remuneraciones.

Por último, los trabajadores alcanzaron un status de interlocutores válidos frente al Estado y los empresarios, posición que si bien fue desconocida continuamente por los empresarios, los obligó a negociar y a transformar el estilo de las relaciones industriales establecidos entre las empresas y sus trabajadores. Lo anterior quedó de manifiesto en las normativas establecidas desde 1924 y, sobre todo después de 1931, en que la institucionalidad laboral fue reorganizada a través del primer Código del Trabajo ${ }^{22}$.

El elevado nivel de contestación y éxito en las movilizaciones de los trabajadores chilenos en general y los carboníferos en particular obligaron a las elites empresariales y al Estado a ejercer la violencia para enfrentar la coyuntura contestataria de los trabajadores, pero, al mismo tiempo, aunque con un diseño a más largo plazo a modificar lo mecanismos para re-equilibrar la relación capital y trabajo, por las acciones de beneficencia de los propios industriales o por el avance en las prácticas asistencialistas del Estado. 


\section{Un nuevo ciclo de movilización social de los trabajadores del carbón. Posición estrategia versus intervencionismo estatal, 1938-1947.}

La dictadura de Carlos Ibáñez y las estrategias de control social implementadas por las empresas lograron contener durante una década la actividad sindical y las demandas de los trabajadores, tanto en la región del carbón como en el conjunto del país. Sin embargo, tras el triunfo del Frente Popular (una coalición de partidos de centro izquierda en que se habían integrado los partidos marxistas) y hasta al menos 1947, la politización de los sindicatos obreros y la eliminación parcial de las restricciones a la organización y expresión del mundo popular, debilitó esa intervención y potenció el desarrollo de un nuevo ciclo de demandas. Aunque no se anuló la capacidad de control empresarial, permitió la inauguración de una etapa en que, una vez más, los trabajadores pusieron a prueba la políticas socializadoras impuestas por las empresas, amparados por el fortalecimiento de sus expresiones de clase, pero también por el reforzamiento de su conciencia acerca del lugar estratégico que ocupaba la minería del carbón en el proyecto industrializador de los gobiernos de centro izquierda. Como en la década del veinte, la política paternalista de los empresarios y el naciente asistencialismo estatal no fueron suficientes para frenar a los trabajadores, que además ponían en peligro el proyecto de modernización capitalista. Nuevamente, como entonces, la salida fue represiva, aunque esta vez enmarcada en la lucha anticomunista con un referente claramente institucional y dotada de una fuerte imagen de legalidad. Había que salvar a los trabajadores carboníferos de las garras del comunismo, una ideología que, de acuerdo a las Compañías y sectores de las clases dirigentes, los manejaba a su antojo y ponía en peligro además la independencia nacional.

La retórica empresarial manifestó su preocupación por las demandas obreras y los efectos producidos sobre la marcha del sector, especialmente sobre el comportamiento de la producción nacional. Así, no dudaron en establecer como verdaderos responsables del mal desempeño de la actividad carbonera a los trabajadores y sus presiones reinvidicativas que, en algunos casos, acusaron de 
antipatrióticas y, en otros, directamente boicoteadoras de la producción nacional con fines políticos. Así ocurrió en "las crisis" de la década de 1920, pero los mismos argumentos volvieron a repetirse en los conflictos recurrentes experimentados en la de 1940, en que las reclamaciones por mejoras en las condiciones de trabajo y vida estuvieron en el centro de los conflictos entre capital y trabajo, tal como quedó de manifiesto en el nuevo ciclo huelguístico desarrollado entre 1940 y 1947 (POBLETE, 1949).

Los representantes de las Compañías y algunos miembros de la derecha conservadora acusaban directamente a los trabajadores de los graves efectos causados sobre el resto de la economía, la insuficiencia de combustible para alimentar las calderas que accionaban el transporte, el alumbrado y la producción industrial nacional, el que debió ser racionado con ocasión a los conflictos que, por el espacio de varias semanas, habían paralizado la producción carbonífera ${ }^{23}$. Si bien en los años cuarenta los movimientos de paralización de actividades fueron más limitados en el tiempo, sus efectos fueron más alarmantes, dado el aumento del consumo interno de carbón chileno. La estrategia de los trabajadores también había cambiado y junto con declarar directamente la huelga, disminuyeron la producción artificialmente, aunque lo desconocieran en términos abiertos. Por su parte, las autoridades centrales veían con espanto la disminución radical de las reservas comerciales de carbón nacional, que en algún momento estuvieron representadas por apenas por 30.000 a 35.000 toneladas, en un país en que se consumían más de dos millones de toneladas de carbón nacional anualmente ${ }^{24}$.

La preocupación por el impacto provocado por la movilización de los trabajadores se manifestó, por ejemplo, en los comentarios publicados por el Boletín Minero, órgano oficial de la Sociedad Nacional de Minería - la mayor organización de empresarios de la minería -, con ocasión de la huelga de octubre de 1947 en el Golfo de Arauco. Entonces manifestó:

La huelga de los obreros de la industria del carbón, que duró del 5 al 24 de octubre, hizo que la producción sufriera un marcado descenso. En total se produjeron en ese mes 114,877 toneladas, esto es, 60,304 toneladas menos que en 
septiembre y también 57,615 toneladas menos que en octubre del año pasado.

En el mes de octubre y parte del de noviembre fue necesario establecer un estricto racionamiento de los servicios de luz y gas en Santiago y Concepción y proceder a la suspensión del recorrido de muchos trenes, con las consiguientes perturbaciones para el país, a fin de evitar que la gran escasez de carbón que se hizo sentir con la disminución de la producción y la falta de stocks obligará a paralizar totalmente la atención de los servicios vitales de la nación. También ha sido necesario importar carbón de los Estados Unidos para reponer las cantidades que se dejaron de producir por la huelga y que son indispensables para el normal desarrollo del país ${ }^{25}$.

Para enfrentar el problema, las estrategias de asistencia social a través del funcionamiento de los Departamentos de Bienestar de las empresas y las reformas institucionales fueron combinadas hábilmente para contrarrestar la dinámica movilizadora de los trabajadores que, a los ojos del empresariado y la autoridad, revestía un serio peligro para la economía pero también para la convivencia democrática del país, dada la cercanía de la agitación social con la actividad desplegada por el Partido Comunista.

La inauguración de esta nueva etapa, coincidiendo con la relativa apertura derivada de la llegada al gobierno de la coalición frente populista, sirvió de punto de inflexión en las relaciones protagonizadas a tres bandas por los trabajadores, las empresas y el Estado, y un nuevo repunte en la organización de los trabajadores y la canalización de sus demandas. Si bien hubo sindicatos que continuaron amparados bajo la tutela empresarial ${ }^{26}$, otros, ocupando la propia institucionalidad estatal, aprovecharon los espacios ofrecidos por la legislación para alcanzar mayor autonomía, hecho reforzado además porque sus dirigencias volvieron a ser de militancia comunista. Esto tuvo además su corolario en que varias de las alcaldías del territorio carbonífero contaron entre sus autoridades a mineros del carbón de filiación comunista o socialista y, entre los representantes provinciales al Congreso Nacional a destacados dirigentes del PCCh, incluso provenientes de la zona del carbón. En esas circunstancias 
el avance de los trabajadores en términos de articulación social y capacidad negociadora volvió a desplegarse. En el corto plazo la Compañías debieron, incluso usando los dispositivos impuestos por el Ministerio del Trabajo, negociar con los trabajadores, lo que las llevó a tener que aceptar sendos aumentos salariales, a escasos dos años de ocurridas las transformaciones políticas. En la mayoría de las situaciones se siguieron las prácticas establecidas por la legislación laboral que propició negociaciones bastante reguladas, que fueron sin embargo alteradas en 1947 cuando los trabajadores desconocieron las propuestas de la empresas, desatándose los conflictos que terminaron unos meses después con la proscripción de las dirigencias sindicales, la militarización de la zona y la exclusión de los comunistas de la vida pública nacional.

Claramente las relaciones entre trabajadores y empresarios cambiaron de fisonomía y tendieron a politizarse y así, mientras los obreros buscaron alianzas y representación entre los partidos de izquierda, especialmente el comunista, aunque también entre socialistas y radicales, las empresas estrecharon sus alianzas con los gremios empresariales, - en este caso especialmente representadas por la Sociedad Nacional de Minería (SONAMI) y la Confederación de la Producción y el Comercio - y con algunos representantes al Congreso Nacional que, como el senador Hernán Videla Lira o el diputado Pedro Poklepovic, compartían intereses y mantenían estrechas relaciones con las Compañías mineras y los gremios empresariales.

Ante esta nueva arremetida de los trabajadores, la solución volvió a ser la misma que se usó para detener los desbordes socializantes de la década del veinte: represión y paternalismo industrial, pero con algunos matices interesantes. Por una parte, las empresas insistieron en su estrategia paternalista a través de políticas simbolizadas por los Departamentos de Bienestar, esta vez combinadas con el asistencialismo estatal que ya había sido puesto en práctica, y servía de paliativo a la crisis del mundo popular.

Si bien la legislación social, ejemplificada por iniciativas como el seguro obrero o la legislación sobre accidentes laborales, armaba un cuadro que constituía un avance importante desde el punto de vista de la seguridad social, no alcanzaba para solucionar los 
problemas de una comunidad sumamente marginada y maltratada por la pobreza y la inseguridad laboral. Los trabajadores politizados exigían el cumplimiento del programa de la coalición de gobierno y si bien los comunistas formaban parte de ella, acompañaban a los mineros en dichas reclamaciones. Fue justamente esa cercanía la que permitió a los sectores más conservadores de la política nacional reafirmar su defensa del régimen económico y asociar la necesidad de control social en la zona minera a las iniciativas que buscaban resguardar el sistema democrático de la amenaza comunista. Entonces la solución a los conflictos del carbón no sólo significaba defender lo que se consideraba como el legítimo patrimonio empresarial de los forjadores de la industria del carbón en Chile, sino también era una muestra de garantía para el funcionamiento del conjunto de la economía nacional. Como si eso fuera poco, la vuelta a la normalidad en la zona carbonífera se haría con la derrota del comunismo y su influencia en los sindicatos, contribuyendo a la cruzada de salvación nacional frente a esa amenaza, que además era mirada con buenos ojos por el capital externo invertido en Chile.

Por lo mismo, el período estuvo marcado por la promulgación de una serie de leyes relacionadas con la seguridad interior del Estado, el otorgamiento de facultades extraordinarias al Presidente de la República y el establecimiento de los llamados "estados de excepción constitucional" que en conjunto permitieron reprimir lo que se consideraba movimientos atentatorios contra los intereses nacionales, de los cuales el comunismo era su principal exponente, aunque no el único ${ }^{27}$. Dicha política represiva fue coronada con la ruptura de la coalición de gobierno a mediados de 1947 y luego por la utilización de sucesivas leyes destinadas a reforzar la autoridad del Presidente de la República con facultades extraordinarias, que permitió reprimir la movilización social y "restaurar el orden" amagado en esa oportunidad.

En el caso de las minas de carbón, las ciudades de Lota y Coronel fueron ocupadas por fuerzas militares (de la marina específicamente) y los trabajadores obligados a reiniciar las tareas productivas, los sindicatos fueron intervenidos y las autoridades municipales de filiación comunista despojadas de sus cargos. 
Dicha política represiva fue reforzada, indudablemente, con la drástica aplicación de la Ley de Defensa de la Democracia, a los sindicatos carboníferos y a los órganos de representación comunal después de septiembre de $1948^{28}$. La aplicación de dicha ley permitió la exclusión de los militantes del Partido Comunista de la vida política, alrededor de 28.000 militantes fueron borrados de los registros electorales, mientras que los dirigentes sindicales fueron apresados y encerrados en un campo de prisioneros en la localidad de Pisagua en el norte del país. Se debe decir que la ley contó con el apoyo de los tradicionales grupos políticos de la derecha conservadora y liberal, así como del partido radical, principal partido de gobierno, mientras que socialistas y comunistas votaron en contra. La ley fue derogada solamente en 1958, para entonces la situación en las minas de carbón se había transformado dramáticamente (DI TELLA, 1966).

\section{Consideraciones finales}

Por muchos años los trabajadores del carbón representaron una particularidad en el mundo del trabajo en Chile, desde los inicios del tránsito al capitalismo hasta bien entrado el siglo XX. Ellos, junto a los trabajadores salitreros y del cobre, se asociaron a espacios de trabajo moderno, donde sus tareas se organizaron progresivamente bajo una estructura productiva de naturaleza capitalista: la segmentación de tareas específicas, el trabajo "cronometrado" y el uso de técnicas, de energías y de una nueva organización para alcanzar los máximos rendimientos.

Esto fue más significativo aún porque la ausencia de núcleos importantes de trabajadores industriales ya sea en los ámbitos del acero, textil o metal mecánico, los convertía en los miembros de la clase obrera más significativos. Tanto por su concentración numérica, como por la posición estratégica ocupada dentro del ordenamiento económico nacional ${ }^{29}$.

Por otra parte, los trabajadores del Carbón, a pesar de la intransigencia de los empresarios y el Estado, - y de la habilidad de ambos para acomodarse a las transformaciones sociales acarreadas por la modernidad -, gozaban de una capacidad de negociación que 
se extendió en el tiempo, con flujos y reflujos, al menos hasta fines de la década de 1950, en que las señales más claras de la crisis estructural de la minería carbonífera comenzaron a hacerse evidentes. Entonces, las ventajas provenientes de su posición estratégica, comenzaron a colapsar, primero por el desplazamiento del carbón como producto energético imprescindible, luego porque la entrada a la era post industrial los convirtió en un sector fosilizado de una economía capitalista que estaba avanzado en nuevas direcciones, no solamente por la transformación de las matrices energéticas, sino por las innovaciones introducidas en el mundo fabril. Esto no sólo provocó acomodos y transformaciones en el arcaico mundo de la producción de carbón, en que muchos trabajadores fueron paulatinamente desvinculados, sino también en sectores industriales que habían sido considerados, hasta ese momento, como símbolos de la vanguardia de la producción industrial mundial, por ejemplo la industria automovilística ${ }^{30}$. A partir de entonces la capacidad de presión y las posibilidades de negociación del los trabajadores del carbón y sus sindicatos se fueron agotando y, de trabajadores que demandaban mejoras salariales y beneficios frente a las cúpulas empresariales y el Estado, se transformaron en actores cuya lucha central era evitar el cierre de sus fuentes laborales.

Con todo, en la etapa que va entre la década de 1920 y fines de la década de los cincuenta permitió que los trabajadores del carbón, y las luchas de sus sindicatos, fueran vistos como parte de la "clase obrera heroica”, en el sentido que utiliza el término Javier Tébar ${ }^{31}$, es decir una clase combativa y poderosa capaz incluso de imponer sus términos, sobre todo después que la declinación de la industria salitrera había hecho desaparecer a un componente social que se ubicaba en los orígenes del movimiento obrero chileno.

Se trataba de una clase de trabajadores, el de los mineros del carbón, colocado en el centro de la actividad productiva, capaz de generar millones de toneladas de carbón, pero también millones de pesos para las empresas y el Estado, y al mismo tiempo capaz de ubicarse como una de las palancas principales, hasta ese momento, de los procesos de modernización productiva que, sobre todo en el ámbito industrial, pero también relativas al transporte, se habían echado a andar. Hasta entonces la modernización todavía iba a ser 
impulsada por el carbón, y hasta que eso no cambió se mantuvo la imagen del trabajador carbonífero como sufrido, abnegado, pero al mismo tiempo combativo y capaz de imponer sus exigencias económicas, y de liderar un movimiento social amplio, con vinculaciones políticas, aunque claramente con flujos y reflujos tal como ocurrió con nuestra propia realidad democrática.

Por otra parte, la movilización de los mineros del carbón fue vista como un peligro frente al cual había que usar diversas estrategias, las más sutiles de cooptación como las derivadas del paternalismo industrial y sus perfeccionados Departamentos de Bienestar, pero también las más severas de naturaleza represiva, pero cuidadosamente revestidas de un carácter de legalidad. Dada la evidente vinculación entre los grandes sindicatos carboníferos y el Partido Comunista, la bandera de lucha de los sectores empresariales, pero también de sectores representativos de las más diversas orientaciones políticas, incluyendo en algunos momentos a radicales y socialistas, estuvo derechamente asociada al deseo de evitar el avance de aquella doctrina. Entonces se apuntaba los dardos no en contra de los trabajadores y su lucha emancipadora, sino sobre quienes los habían contaminado con sus ideas disolventes.

Con todo, los propios trabajadores se vieron a sí mismos como una pieza importante del engranaje productivo, lo que ayudó a consolidar su identidad no sólo como grupo de trabajadores asociados a una actividad particular y a la idea de conformar una comunidad única, aunque también lo hicieron, sino también como sujetos capaces de defender sus intereses y movilizar a otros actores, ya sea en el ámbito regional, pero también a escala nacional.

Fueron percibidos como un peligro, sobre todo cuando los trabajadores aprendieron que sus movilizaciones debían estar ligadas a momentos claves de evolución de la economía chilena. Eso tenía que ver con la percepción de aquellos momentos de mayor necesidad del combustible fósil; cuando los precios habían aumentado, y no así sus salarios, o cuando las reservas comárcales de los grandes consorcios carboníferos estaban por agotarse y se corría el peligro o se tenía la posibilidad, todo depende desde donde se mire, de poner en jaque el abastecimiento. Sin duda lo que dominaba era 
su percepción, y la situación real, de estar ocupando una posición estratégica $^{32}$.

La arremetida neoliberal de fines de los setenta terminó por sepultar esa capacidad y la escasa viabilidad del carbón chileno, en términos económicos, fue el mejor argumento para cerrar su ciclo extractivo en la década de los 90. Sin embargo, si bien las transformaciones económicas de matriz liberal ensayadas en Chile, dieron el golpe de gracia a la industria del carbón, a sus trabajadores y al espacio cultural que habían construido, el debilitamiento de la viabilidad de la extracción del carbón había comenzado su derrumbe al menos en las dos décadas precedentes. Cuando finalmente la mina de Schwager cerró sus puertas en 1995 y la de Lota en abril de 1997 , la historia de la pérdida del lugar estratégico del carbón y sus trabajadores llevaba casi 30 años en su marcha de deterioro inexorable.

\section{THE STRATEGIC POSITION OF COAL WORKERS IN CHILE. FROM FORTRESSES TO THE CRISIS, 1920-1960.}

Abstract: This article discuses the behavior of Chilean coal mining companies and workers, specifically in the principal coal mining region of Arauco. It explains how the performance of the companies and the attempts of national modenization through industrialization, strongly dependent on the production of fossil fuel, were challenged, with relative success, by the demands of the worked who had politicized and became conscious of the strategic position that they were occupying in the Chilean economy. This was possible until fossil fuel was replaced by other energy sources, leading to the lengthy decline of coal mining in the country. Keywords: Mining. Coal. Social mobilization. Strategic position.

\section{Notas}

${ }^{1}$ Este artículo forma parte de los resultados del proyecto No 79090004 . Estudios regionales e historia del tiempo presente. La región del Bío-Bío, colapsos, reconversión productiva y crisis identitaria, 1948-2008. Programa Capital Humano Avanzado, CONICYT.

${ }^{2}$ DUNLOP, John (1948). Citado por WOMACK, John (2007) cap. II.

${ }^{3}$ ARANCIBIA, Luis (1921).

${ }^{4}$ La segunda ciudad más importante de Chile, hasta la actualidad. 
${ }^{5}$ Fueron evidentes las respuestas especulativas de las empresas carboníferas al cierre de los mercados externos de combustibles, motivado, por ejemplo, por las dos guerras mundiales o la crisis de 1930. Los precios del carbón nacional crecieron a niveles exorbitantes, como también las utilidades de las Compañías en relación al capital inicial invertido, tal como aparece consignado en el Informe de la Comisión del Carbón, en el año 1926.

${ }^{6}$ La Compañía Minera y Fundición de Schwager se formó en 1892, mientras que la nueva Compañía Minera e Industrial de Chile lo hizo en 1921.

${ }^{7}$ Un Informe de la Oficina del Trabajo, afirmaba que ente 1909 y 1920 el costo de la vida había aumentado un $62,92 \%$, lo salarios en un $58 \%$, mientras que el precio del carbón había crecido un $876 \%$, durante la misma etapa. Boletín de la Oficina General del Trabajo Volumen n. 15.

${ }^{8}$ Sociedad Nacional de Minería (SONAMI), Boletín Minero, n. 390, 1931.

${ }^{9}$ Compañía Carbonífera e Industrial de Lota, Memoria, 1946.

${ }^{10}$ Chile, Servicio Nacional de Estadísticas, Minería, 1946.

${ }^{11}$ La fusión de las dos Compañías fue formalizada por el Decreto Supremo n. 686, de 29 de febrero de 1964.

${ }^{12}$ Con anterioridad se habían formalizado en Lota y Lebu sociedades de socorros mutuos que se identificaban con la protección y regeneración de los trabajadores asociados.

13 Archivo de la Oficina del Trabajo, volumen n. 87. Informe del Inspector Regional del Trabajo al Director de la Oficina, 10 de mayo de 1921.

${ }^{14}$ Dirección General del Trabajo, Informe del Inspector Regional del Trabajo, 30 de agosto de 1927.

${ }^{15} \mathrm{El}$ concepto de recinto refiere a un espacio controlado directamente por la Compañía, que impone sus normas, con recursos propios y muchas veces en contradicción con las autoridades locales.

${ }^{16}$ Dirección General del Trabajo, Informe del Inspector Regional del Trabajo, 30 de agosto de 1927 p. 7.

${ }^{17}$ Ibid, p. 8.

${ }^{18}$ Ver KLUBOCK, Thomas (1995).

${ }^{19}$ Dirección General del Trabajo, Informe del Inspector Regional del Trabajo, 30 de agosto de 1927 , p. 9.

20 Archivo de la Oficina del Trabajo, Volumen 92, Comunicación del Consejo Federal de Schwager al Ministro del Interior, p. 2.

${ }^{21}$ La noción del trabajo incesante domina en las esferas industriales después de iniciado el camino hacia la estructuración taylorista, centrada en hacer la actividad del trabajador una acción sin pausa y lo más productiva posible, terminando con los "tiempos muertos" en el desempeño de los obreros. Ver CORIAT, Benjamín (2001); y COHEN, Daniel (2007). 
${ }^{22}$ Poblete, M. El derecho del trabajo y la seguridad social en Chile, especialmente el capitulo II, La conciliación, el arbitraje y las huelgas en Chile. Santiago: Editorial Jurídica, 1949. Ver también el completo y reciente trabajo interpretativo de YÁÑEZ, Juan Carlos (2008).

${ }^{23}$ En noviembre de 1920, el Senador Barros Errázuriz (senador por la provincia de Linares) denunciaba la extrema gravedad acarreada por el conflicto carbonífero "Quiero insistir una vez más acerca de la gravedad que tiene esta situación de huelga permanente en que se encuentran desde hace ya algún tiempo los obreros de la zona carbonífera...las consecuencias que ha creado esta situación son enormes. El servicio de ferrocarriles está ya de hecho paralizado en todo el país". Boletín Sesiones del Senado, Sesión extraordinaria n. 34, 23 de noviembre de 1920. ${ }^{24}$ Chile, Dirección Nacional de Estadísticas, Minería, 1948.

${ }^{25}$ SONAMI, Boletín Minero, no 573, enero de 1948, p. 33.

${ }^{26}$ Ver, por ejemplo, los Estatutos del Sindicato Profesional de Empleados de la Compañía Carbonífera e Industrial de Lota, fundado en Lota el 26 de junio de 1939. Concepción: Soc. Imprenta y Litografía. 1940.

${ }^{27} \mathrm{La}$ trayectoria de la legislación destinada a fortalecer las políticas de "seguridad interna en Chile", se encuentra detallada en el trabajo de HUNEEUS, Carlos (2009).

${ }^{28}$ La Ley de Defensa Permanente de la Democracia, fue discutida en el Congreso Nacional y promulgada en septiembre de 1948. Mantuvo a los miembros del Partido Comunista fuera de la ley por casi 10 años, pero además se utilizó para hostigar a otros grupos que intentaban transformar las relaciones sociales dentro del país, tal como ocurrió con organizaciones sindicales relacionadas con la Iglesia Católica.

${ }^{29}$ De acuerdo a un informe de la Sociedad de Fomento Fabril publicado en 1920, durante el período 1912 y 1918 hubo en Chile un promedio cercano a los 70.705 trabajadores industriales. Sin embargo, estaban distribuidos entre 6.750 fábricas o talleres, lo que señala un promedio de poco más de 10 operarios por unidad. Ver, GONZÁLEZ, L. (1920, p. 7).

${ }^{30} \mathrm{Al}$ respecto son muy esclarecedores los trabajos de HÖBEL, Alexander (2011) y el de LILLO, N. (2011) incluidos en el texto colectivo editado por TÉBAR, Javier. El movimiento obrero en la ciudad. De la movilización sociopolitica a la crisis económica. Barcelona: Editorial El viejo Topo, 2011.

${ }^{31}$ TÉBAR, Javier (2011, p. 14).

${ }^{32}$ Volvemos a ocupar la perspectiva ofrecida por John Womack, tesis que suscribimos para el caso de los trabajadores de la minería del carbón. 


\section{La posición estratégica de los trabajadores...}

\section{Referencias}

ARANCIBIA, Luis. La región Carbonifera, considerada en sus aspectos social y minero, Memoria de Prueba para optar al Grado de Licenciado en Leyes y Ciencias Políticas. Santiago de Chile: Universidad de Chile, 1921.

COHEN, Daniel. Tres lecciones sobre la sociedad postindustrial. Madrid: Katz Editores, 2007.

COMISIÓN DEL CARBÓN, Informe, Santiago, 1926.

COMPAÑÍA CARBONÍFERA E INDUSTRIAL DE LOTA. Balance y Memoria, 1947, 1948.

CORIAT, Benjamín. El taller y el Cronómetro. Ensayo sobre el taylorismo, el fordismo y la producción en masa. Madrid: Siglo XXI, 2001.

DI TELLA, Torcuato; BRAMS, Lucien; REYNAUD, Jean Daniel; TOURAINE, Alain. Sindicato y Comunidad. Dos tipos de estructura sindical latinoamericana. Buenos Aires: Editorial del Instituto Torcuato Di Tella, 1967.

DUNLOP, John. The Development of Labor Organization: A Theoretical Framework. In: LESTER, Richard; SHISTER, Joseph (Eds.). Insights into Labour issues, 1948.

FIGUEROA, Consuelo. Revelación del subsole. Las mujeres en la sociedad minera del carbón, 1900-1930. Santiago: ICSO - Centro de Investigaciones Barros Arana, 2009.

FIGUEROA, Enrique; SANDOVAL, Carlos. Carbón: cien años de historia (1848 - 1960), Santiago: CEDAL, 1987.

GONZÁLEZ, Pedro. Chile. Breves noticias de sus industrias. Santiago: Sociedad Imprenta y Litografía Universo, 1920.

HÖBEL, Alexander. Las luchas en el "triangolo industriale" italiano y la revolución del país, 1960-1980. In: TÉBAR, Javier. El movimiento obrero en la ciudad. De la movilización sociopolítica a la crisis económica. Barcelona: Editorial El viejo Topo, 2011.

HUNEEUS, Carlos. La Guerra Fría chilena. Gabriel González Videla y la ley maldita. Santiago: DEBATE, 2009.

KLUBOCK, Thomas. Hombres y mujeres en El Teniente. La construcción de género y clase en la minería chilena del cobre, 1904-1951. In: GODOY, L. et al. Disciplina y desacato. Construcción de identidad en Chile, siglos XIX y XX. Santiago: SUR/CEDEM, 1995.

LILLO, Natacha. Desde los tiempos del baluarte de la Renault en Billancourt hasta los estragos de la discriminación social y étnica (1960-2005). In: TÉBAR, 
Javier. El movimiento obrero en la ciudad. De la movilización sociopolítica a la crisis económica. Barcelona: Editorial El viejo Topo, 2011.

MAZZEI, Leonardo. Orígenes del establecimiento británico en la región de Concepción y su inserción en la molinería del trigo y en la minería del carbón. In: Historia, n. 28, 1992. p. 217-239.

. Los británicos y el carbón en Chile. In: Atenea, n. 475, 1997. p. 137-167. . Expansión de gestiones empresariales desde la minería del norte a la del carbón, Chile, siglo XIX. In: Boletín de Historia y Geografía, Santiago n. 14, 1998. p. 249-265.

- Matías Cousiño antes de Lota: Formación y proyecciones de un empresario minero. In: Atenea, n. 480, 1999. p. 85-128.

ORTEGA, Luis. La industria del carbón de Chile entre 1840 y 1880. In: Cuadernos de Humanidades, n. 1. Santiago: Facultad de Humanidades, Universidad de Santiago de Chile, 1988.

. La Frontera Carbonífera, 1860-1900. In: Revista Mapocho, Santiago, n. 31, 1992. p. 131-148.

PALMA, Gabriel. Chile de economía exportadora a sustitutiva de importaciones, 1914-1935. In: Revista Cieplan, Santiago, n. 12, 1982. p. 61-88.

POBLETE, Moisés. El derecho del trabajo y la seguridad social en Chile. Santiago: Editorial Jurídica, 1949.

SINDICATO Profesional de Empleados de la Compañía Carbonífera e Industrial de Lota, fundado en Lota el 26 de junio de 1939. Estatutos. Concepción: Soc. Imprenta y Litografía, 1940.

TÉBAR, Javier. El movimiento obrero en la ciudad. De la movilización sociopolitica a la crisis económica. Barcelona: Editorial El viejo Topo, 2011.

VENEGAS, Hernán. La huelga grande del carbón. 1920. In: Revista Chilena de Historia y Geografía, Santiago, n. 160, 1992. p. 225-249.

. Crisis y conflictos sociales y políticos en la zona carbonífera. 1918-1931. In: Revista Contribuciones Científicas y Tecnológicas, Área Ciencias Sociales y Humanidades, Universidad de Santiago de Chile, Santiago, n. 116, 1997. p. 125-153.

. Desafíos de la industria carbonífera en Chile. Intervención del sector público en la senda del Estado Benefactor. 1920-1940. In: Revista de Historia, Universidad de Concepción, Concepción, Año 8, n. 8, 1998. p. 151-173. 
La posición estratégica de los trabajadores...

. Crisis de la minería, tensiones sociales y respuesta estatal en Chile, 1920. In: Contribuciones Cientificas y Tecnológicas, Universidad de Santiago de Chile. Santiago, n. 122, p. 77-98. 1999.

. El Carbón de Lota. Textos y fotografías a fines del siglo XIX. Santiago: Editorial Pehuén, 2008.

WOMACK, John. Posición estratégica y fuerza obrera. Hacia una nueva historia de los movimientos obreros, México: Fondo de Cultura Económica, 2007.

YÁÑEZ, Juan Carlos. La intervención social en Cbile, 1907-1931, Santiago: RIL editores, 2008.

Recebido em: 18/07/2011

Aprovado em: 21/12/2011 